This is the author's final, peer-reviewed manuscript as accepted for publication. The publisher-formatted version may be available through the publisher's web site or your institution's library.

\title{
Using the Theory of Planned Behavior to Elicit Restaurant Employee Beliefs about Food Safety: Using Surveys versus Focus Groups
}

Valerie K. Pilling, Laura A. Brannon, Kevin R. Roberts, Carol W. Shanklin, Amber D. Howells

\section{How to cite this manuscript (APA format)}

If you make reference to this version of the manuscript, use the following citation format:

Valerie K. York; Laura A. Brannon; Kevin R. Roberts; Carol W. Shanklin; Amber D. Howells. (2009). Using the Theory of Planned Behavior to Elicit Restaurant Employee Beliefs about Food Safety: Using Surveys Versus Focus Groups. Retrieved from http://krex.ksu.edu

\section{Published Version Information}

Citation: York, Valerie K. , Brannon, Laura A. , Roberts, Kevin R., Shanklin, Carol W. and Howells, Amber D.(2009) 'Using the Theory of Planned Behavior to Elicit Restaurant Employee Beliefs about Food Safety: Using Surveys Versus Focus Groups', Journal of Foodservice Business Research, 12: 2, 180 - 197.

Copyright: Copyright ( Taylor \& Francis Group, LLC

Digital Object Identifier (DOI): DOI: 10.1080/15378020902910777

Publisher's Link: http://www.informaworld.com/openurl?genre=article\&issn=1537-8020 $\&$ volume $=12 \&$ issue $=2 \&$ spage $=180$

This item was retrieved from the K-State Research Exchange (K-REx), the institutional repository of Kansas State University. K-REx is available at http://krex.ksu.edu 
Using the Theory of Planned Behavior to Elicit Restaurant Employee Beliefs about Food Safety: Using Surveys versus Focus Groups 
Using the Theory of Planned Behavior to Elicit Restaurant Employee Beliefs about Food Safety:

\title{
Using Surveys versus Focus Groups
}

\author{
Valerie K. Pilling \\ Laura A. Brannon \\ Kevin R. Roberts \\ Carol W. Shanklin \\ Amber D. Howells
}

\begin{abstract}
Within the framework of the Theory of Planned Behavior (Ajzen, 1991), this study compared the relative usefulness of utilizing a focus group or survey methodology when eliciting restaurant employees' beliefs about performing three important food safety behaviors (handwashing, using thermometers, and cleaning and sanitizing work surfaces). Restaurant employees completed both a survey and focus group interview assessing their beliefs about food safety. Results obtained through surveys were observed to be comparable to focus groups, suggesting researchers employ the less expensive and less time-consuming survey methodology. The strengths and weaknesses of each method are discussed. Specific salient beliefs (e.g., advantages, barriers, etc.) about the behaviors offer implications for workplace food safety interventions and training.
\end{abstract}

Keywords: food safety, handwashing, thermometers, cross contamination, theory of planned behavior, focus groups, surveys, attitudes, perceived control, subjective norms 
Introductory note: Valerie K. Pilling, M.S., Ph.D. Candidate in Psychology, Kansas State University, vpilling@,ksu.edu, 492 Bluemont Hall, Kansas State University, 66506; Laura A. Brannon, Ph.D., Associate Professor of Psychology, Kansas State University, lbrannon@ksu.edu, 492 Bluemont Hall, Kansas State University, 66506; Kevin R. Roberts, M.S., Ph.D. Candidate in Hotel, Restaurant, Institution Management \& Dietetics, Kansas State University, roberts@humec.ksu.edu, 104 Justin Hall, Kansas State University, 66506; Carol W. Shanklin, Ph.D., R.D., Associate Dean of the Graduate School, Kansas State University, shanklin@ksu.edu, 103 Fairchild Hall, Kansas State University, 66506; Amber D. Howells, Graduate Student in Hotel, Restaurant, Institution Management \& Dietetics, Kansas State University, amberkstate@yahoo.com, 104 Justin Hall, Kansas State University, 66506.

This project was partially funded through a grant from the National Integrated Food Safety Initiative (Grant No. 2004-51110-02170) of the Cooperative State Research, Education, and Extension Service, U.S. Department of Agriculture. 


\section{Introduction}

The Theory of Planned Behavior (TpB; Ajzen, 1991) is one of the most widely implemented models for understanding and changing health beliefs and behaviors. According to the TpB, the best predictor of a person's behavior in any given situation is his or her intention with respect to the behavior. A person's behavioral intention is based upon three antecedents: his or her attitudes, subjective norms, and perceived behavioral control over performing the behavior. When utilizing the TpB to change participants' behaviors, it is necessary to first elicit participants' salient beliefs regarding the specific behaviors of interest. Beliefs are elicited about advantages and disadvantages of performing the behavior (attitudes), barriers and facilitators to performing the behavior (perceived behavioral control), and people who care about whether or not the behavior is performed (subjective norms). Knowledge of these beliefs allows the researcher to construct a more comprehensive $\mathrm{TpB}$ survey that is used to test the theory, the results of which may be used to design an intervention to change participants' beliefs and behaviors. Therefore, when using the $\mathrm{TpB}$, there is first a belief elicitation and scale construction stage, then later a scale application and theory testing stage. The current study is interested in the belief elicitation.

Researchers have suggested that salient beliefs be elicited through focus groups or surveys. While reviewing the literature, the researchers encountered different methodologies utilized for belief elicitation, with some research using paper and pencil surveys (e.g., Crawley \& Koballa, 1992; Nash, Edwards, \& Nebauer, 1993; Sparks \& Shepherd, 2002), some using focus group interviews (e.g., McCarty, Hennrikus, Lando, \& Vessey, 2001; Millstein, 1996; Sheehan et al., 1996), and others using both (e.g., Harrison \& Liska, 1994; Randall \& Gibson, 1991). 
The current research sought to determine if paper surveys produce comparable results to focus groups. It is important to empirically determine whether the two data collection methods are comparable; if similar results can be obtained though the use of both techniques, surveys may have some advantages. For example, collecting data through surveys is generally easier. Today, people are very busy. It is more convenient for someone to complete a survey on their own time rather than having to fit a focus group session into their schedule and successfully show up at a specific time and place. Surveys are generally more time efficient and more cost effective. Most of the steps in the process are identical for using surveys and focus groups (e.g., the question development, participant recruitment, incentives offered for participation, data entry, data analysis, and report preparation). However, using surveys only involves additional costs for printing, envelopes, labels, postage and return postage as well as labor for preparing the surveys to be mailed. Alternately, if a researcher could deliver the surveys to the restaurant employees at work, it would just require printing, funds for mileage, and employee time for delivering and retrieving the surveys. On the other hand, focus group interviews have costs associated with renting facilities and providing refreshments for participants as well as many more labor requirements by way of interview guide development, training and practicing for the interviewer and recorder of the focus groups, the interviewer's and recorder's time spent conducting several focus group sessions, and transcribing tape and notes. In some instances, a trained focus group facilitator is hired to conduct the focus group sessions because such an individual would have no preconceived idea of the expected outcomes of the session which would potentially reduce the bias in obtaining responses to the questions. This would significantly increase the labor cost of conducting the focus groups. These labor related costs would be higher both because these tasks are more time-consuming and the skill required is more sophisticated compared to the labor 
required for preparing mailings. Given the advantages of surveys, the importance of determining the comparability of focus group interview results and survey results is clear.

Research Application: Food Safety in Restaurants. The current study applied methodologies used in previous Theory of Planned Behavior research to identify factors that may be related to restaurant employees engaging or not engaging in three specific food safety practices: handwashing, using a thermometer, and sanitizing food contact surfaces. These three particular behaviors were chosen for investigation because they are the three most commonly implicated factors in foodborne illness and disease (Collins, 1997; Food and Drug Administration, 2004; National Restaurant Association Educational Foundation, 2004). Food safety is an important issue to investigate because it has an impact on many individuals and society in general. In the United States each year, millions of people are victims of foodborne illnesses resulting in illness, hospitalization, or death (CDC, 2005). Further, society endures annual costs for these foodbore illnesses and diseases estimated at $\$ 6.9$ billion (Economic Research Service, 2004).

Food preparers not using proper food safety practices are frequently implicated as a risk factor in foodborne illness outbreaks (Collins, 1997; Food and Drug Administration, 2004; National Restaurant Association Educational Foundation, 2004). Additionally, when foodborne illnesses are investigated, the origin is usually traced back to a restaurant (Council for Agriculture Science and Technology, 1994; Economic Research Service, 1996; Olsen, MacKinon, Goulding, Bean, \& Slutsker, 2000; Riben, et al., 1994). Both full-service and fast food establishments are reported to be out-of-compliance with major food safety standards such as time/temperature abuse ( $64 \%$ and $2 \%$ out-of-compliance, respectively), substandard personal hygiene ( $43 \%$ and $31 \%$, respectively), and contamination of equipment/food contact surfaces 
(37\% and 22\%, respectively) (Food and Drug Administration, 2004). Investigating food safety in restaurants appears to be particularly important compared to other food sources. The number of instances of restaurant employees being out-of-compliance with food safety standards is higher than those of food handlers employed in nursing homes, hospitals, and elementary schools (Food and Drug Administration, 2000).

One contributing factor appears to be a lack of dedication to food safety. Not all chain and independently owned restaurants have explicit policies regarding food safety practices such as handwashing (only $61 \%$ and $17 \%$ have them, respectively), the use of gloves (56\% and $12 \%$, respectively), and taking the temperature of foods at the completion of cooking ( $64 \%$ and $32 \%$, respectively) (Roberts, Barrett, \& Sneed, 2005). Even when there is a policy in place, while it may be more likely employees will comply with proper food safety regulations, they are not necessarily going to do so. However, it is very unlikely that employees are going to adhere to proper food safety practices if there are no explicit policies in place in their establishment. Therefore, it is clear the manager's role is a crucial one in ensuring food safety regulations are followed. Research has already investigated restaurant managers and found that those who had more favorable attitudes toward food safety score higher during inspections than those who did not have such favorable attitudes (Cochran-Yantis et al., 1996). Restaurant managers also indicate that they would be more likely to institute food safety policies if they had more time, money, and employee interest (Roberts \& Sneed, 2003). However, research has not yet investigated restaurant employees' attitudes toward food safety, even though they handle the food and are most directly responsible for ensuring food safety is practiced. For this reason, it is important to go directly to the source and study restaurant employees. 
Past research has suggested that restaurant employees' unsafe food handling is not resulting solely from a lack of knowledge of food safety (Howes, McEwen, Griffith, \& Harris, 1996). While some past research has found either observed (Cohen, Reichel, \& Schwartz, 2001; Cotterchio, Gunn, Coffill, Tormey, \& Barry, 1998; Kneller \& Bierma, 1990) or self-reported (McElroy \& Cutter, 2004) improvements in food safety after training has taken place, Howes et al. (1996) reported that even when restaurant employees are trained in proper food handling, the employees still do not practice safe food handling. Due to the inconsistency in past research, the issue deserves further attention. Further, due to the findings of Howes et al. (1996) it is important to investigate factors other than knowledge that may contribute to employees' poor food handling practices. The TpB offers an excellent model for investigating such factors as it states that behavioral intention (and ultimately the performance of the behavior) is a product of attitudes, perceived control, and other people's attitudes (subjective norms) toward performing the behavior.

The most common risk factors resulting in foodborne diseases and illnesses (which are largely due to food handlers not taking proper care of food) are improper holding times and temperatures, cross contamination, and poor personal hygiene (Collins, 1997; Food and Drug Administration, 2004; National Restaurant Association Educational Foundation, 2004). Therefore, this study investigates restaurant employees' attitudes, perceived control, and subjective norms relating to using thermometers, proper handwashing, and cleaning and sanitizing food contact surfaces.

Ajzen, the creator of the $\mathrm{TpB}$, described the elicitation of salient beliefs as input for survey development (Ajzen, 1991). Some researchers have opted to use surveys, focus groups, or both methods for this belief elicitation. However, no research to date has empirically determined 
the comparability of results obtained through the two methods. The current study sought to evaluate if both methods do, in fact, result in comparable information. Within the context of the $\mathrm{TpB}$, the objective of an elicitation focus group or elicitation survey is the same, to identify salient beliefs. The researchers wanted to use methods that are consistently used in research applying the TpB. Since both methods had previously been used, the researchers wanted to investigate if the quantity of beliefs elicited was the same with focus groups and surveys and to explore if one method was more economical than the other. By collecting this information though both focus group and survey methodology, the researchers could evaluate the relative effectiveness of the two methodologies at assessing participants' most salient beliefs.

The use of the $\mathrm{TpB}$ in food safety research is justified because the theory has been used in various workplace settings to better understand and influence employee behavior. For example, it is utilized to better understand healthcare professionals' behavior towards patients (e.g., Godin, Naccache \& Fortin, 1998; Godin, Naccache, Morel \& Ebacher, 2000; Jenner, Watson, Miller, Jones \& Scott, 2002; Levin, 1999; Liabsuetrakul, Chongsuvivatwong, Lumiganon \& Lindmark, 2003; O’Boyle, Henly \& Larson, 2001). The theory is employed to understand ethical decision-making in the workplace (e.g., Flannery \& May, 2000; Kurland, 1995; Randall \& Gibson, 1991), employee health (e.g., Boudreau, Godin, Pineau \& Bradet, 1995; Harrison \& Liska, 1994; Sheeran \& Silverman, 2003), and employee compliance with workplace policies (e.g., Boissonneault \& Godin, 1990). It has been applied in academic settings to improve student health (e.g., Astrom \& Mwangosi, 2000; James, Tripp, Parcel, Sweeney \& Gritz, 2002; Martin, Hodges-Kulinna, Eklund \& Reed, 2001). Further, Coleman, McGregor, Hemsworth, Boyce, and Dowling (2003) and Sparks, Shepherd, and Frewer (1995) used the TpB to investigate behaviors in food production that may affect food quality. 


\section{Methods}

Thirty-four restaurant employees served as participants in the study. Employees from several local restaurants were given the opportunity to register to participate in focus group interviews in exchange for $\$ 20$. Any employees whose job involved food preparation tasks were allowed to participate. They were told that the researchers were interested in discussing food safety issues and the work environment in the food production area where they were employed. Those who agreed to participate were given a questionnaire to complete and return to the researcher at the time of the focus group interview. The questionnaire contained the exact questions that would be asked during the focus group interview. Each participant attended one of the ten focus group interviews. The number of employees in each focus group ranged from two to nine. The length of the focus groups ranged between 40 and 60 minutes. The Institutional Review Board at the university approved the research protocol.

When the participants arrived for the focus group interviews, they were first required to sign an informed consent form and complete a demographics survey. Next, the interviewer began the session by welcoming the participants, introducing the aim of the focus group interviews (including which behaviors would be discussed), and describing the process that would be used. The participants were asked to respond to all of the questions either based on their current job in food production or any other jobs they may have had in the past working in food production. Though the participants had already given informed consent, the researcher once again reiterated that their participation was voluntary, refusal to participate would involve no penalty and that they could discontinue participation at any time without penalty. They were also told that their individual responses would be kept completely confidential and all data would be reported as group data. 
The interviewer then began asking the focus group questions. The interviewer introduced the behaviors of interest, giving detailed definitions of the behaviors (See Table 1).

Insert Table 1 about here.

In open-ended format, the participants were asked to respond to questions about each of the three food safety behaviors. Participants were asked about their attitudes about performing each behavior. For example, for the behavior "Handwashing," participants were asked "What are some good things that could result from proper handwashing through this practice? (What are some reasons why you or other employees would want to do it?)" and "What are some bad things that could result from proper handwashing through this practice? (What are some reasons why you or other employees might not want to do it?)." Participants were also asked about their perceived control beliefs with the questions "What makes (or would make) it easier for you (or other employees) to properly wash hands through this practice?" and "What makes it difficult for you (or other employees) to properly wash hands through this practice?" Similar questions were asked for the other two behaviors of interest; just replacing the reference to the behavior in the question. The order of the discussion of the three food safety behaviors was counterbalanced to avoid order effects. At the end, the participants were asked about their subjective norm beliefs for all three behaviors through the question "List all the people that you think care (either approve or disapprove) about whether or not you and other employees follow these food safety practices (proper handling of food and work surfaces, proper handwashing, and using a thermometer to check the temperature of food)."

While the interviewer asked the participants questions about their attitudes, perceived control, and subjective norm beliefs regarding the three food safety behaviors, a second 
researcher recorded their responses. The interviewer allowed ample time for responses, repeating each question several times. After the interviewer finished asking all the focus group questions, he collected the surveys the participants had been asked to complete and bring to the session. Finally, the participants were debriefed and paid $\$ 20$.

The questionnaire data and the focus group data were coded by the researcher who recorded the focus group responses. This recorder was also involved in developing the initial coding scheme. Participant responses were coded based on a coding scheme the researchers had developed in a prior data collection. From the previous data collection, the researchers had developed a coding scheme based on the themes that emerged in the responses when giving the same questionnaire to undergraduate hospitality and general psychology classes. For each questionnaire item (e.g., advantages of using a thermometer), the researchers grouped similar responses together to form a single category. For example, when participants are asked "What are some good things that could result from using a thermometer to check the temperature of foods through this practice? (What are some reasons why you or other employees would want to do it?)," responses such as "food safety," "kills microorganisms," and reduces foodborne illness" would all be grouped together into a category labeled "food safety." Other responses like "food quality," "ensures hot or cold food," and "better taste" were grouped together in a category labeled "food quality." Decisions about other responses such as "food is good" were more difficult to place as it could be placed in ether of these categories based on different interpretations. Discussion resulted in placing this response in the category "food quality" as there is a difference between good food and safe food. Responses that were given by very few participants were grouped into a category labeled "Other." For example, one participant listed "knowing where thermometers are" which did not fit into any category, so it was coded into the 
"Other" category. In the previous data collection, two trained researchers coded the data independently. The initial inter-rater reliability of $87 \%$ agreement was improved to $100 \%$ after discussion.

The independent variable is method of data collection with two levels: survey and focus group. The dependent variables of interest are the number of unique belief responses obtained through each method and the frequencies of the specific belief responses. The researcher calculated the number of unique belief responses for each category (advantages, barriers, etc.) within the framework of the TpB for the survey data and the focus group data, separately.

Results

\section{Participant Characteristics}

Among the 34 participating restaurant employees, there were comparable numbers of males (52.9\%) and females (47.1\%). Participants' mean age was 24.92 , though they ranged between 18 and 52 years of age. There were approximately equal numbers of full-time (51.4\%) and part-time (48.6\%) employees. Participants, on average, had been employed 6.47 years in food service, though experience ranged between nine months to 27 years.

\section{Number of Unique Belief Responses}

First, the number of unique belief responses obtained through each method was calculated (Table 2).

Insert Table 2 about here.

The trends of the data suggest that conducting focus groups results in a greater number of unique responses than elicitations of beliefs through surveys. Generally, focus groups provide more 
detailed information than surveys. Across behaviors, benefits ranged from no benefit to seven additional items elicited.

\section{Overall Most Frequent Belief Responses}

The frequency of each specific belief response was calculated. The most frequent responses obtained through the two different methods were compared (Table 3a-c). In general, the most frequently mentioned responses were similar across the two methods. Below we discuss the most common beliefs that were listed using both methods.

\section{Most Frequent Beliefs about Handwashing}

Most Frequent Attitude Beliefs about Handwashing. The most frequently listed advantages of handwashing are improved food safety, reduced cross contamination, and personal hygiene (Table 3a).

Insert Table 3a about here.

The most frequently listed disadvantages of handwashing were that it takes time, it dries hands, it is an inconvenience, and the costs associated with it (water, soap, paper towels).

Most Frequent Perceived Control Beliefs about Handwashing. The most frequently listed factors that would make handwashing easier were having sinks available, having sinks conveniently located, and having training on how to properly wash hands (Table 3a). The most frequently listed barriers to handwashing were not having enough time, resources not being conveniently located, employees having a negative attitude, and having competing tasks. 


\section{Most Frequent Beliefs about Using Thermometers}

Most Frequent Attitude Beliefs about Using Thermometers. The most frequently listed advantages of using thermometers were ensuring the correct temperatures, food safety, food quality, and customer satisfaction (Table 3b).

Insert Table $3 b$ about here.

The most frequently listed disadvantages of using thermometers were the possibility of cross contamination if the thermometer is not properly sanitized between uses, the time it takes, the possibility of doing it incorrectly yet perceiving a false sense of security that the food was safe, and the task competes with other tasks.

Most Frequent Perceived Control Beliefs about Using Thermometers. The most frequently mentioned factors that would make using thermometers easier were having training on the proper use of thermometers, having thermometers available, and having managers monitoring employees' usage of thermometers (Table 3b). The most frequently listed barriers to using thermometers were not having enough time and not having thermometers available.

\section{Most Frequent Beliefs about Properly Handling Food Contact Surfaces}

Most Frequent Attitude Beliefs about Properly Handling Food Contact Surfaces.

Participants most frequently listed the advantages of properly cleaning food contact surfaces as reduced cross contamination, food safety, a clean work area, and protecting the establishment from lawsuits (Table 3c). 
The most frequently listed disadvantages of properly handling food contact surfaces were that it takes time, the possibility of contamination if employees are careless, the task is an inconvenience, and it gives employees a negative attitude.

\section{Most Frequent Perceived Control Beliefs about Properly Handling Food Contact}

Surfaces. The most frequently mentioned factors that would make properly handling food contact surfaces easier to perform were having more time, having managers monitor work in the kitchen, having resources conveniently located, and having training on how and when to properly clean food contact surfaces (Table 3c). The most frequently listed barriers to properly handling food contact surfaces were not having enough time, employees having a negative attitude, and a lack of space.

\section{Overall Most Frequent Subjective Norm Beliefs}

The participants were asked about their subjective norm beliefs just once, for all three of the food safety behaviors. While the focus groups and surveys resulted in the same most frequently listed subjective norms, they were listed in different orders in the two methods. The subjective norms identified by the most focus groups were employees (mentioned by $100 \%$ of focus groups) and health inspectors (100\%), then customers (90\%) and managers (90\%). In surveys, participants most frequently mentioned customers $(73.5 \%)$, then employees $(61.8 \%)$, managers (58.8\%), and health inspectors $(47.1 \%)$.

\section{Discussion}

Using Surveys versus Focus Groups. The results suggest that the preferred method for eliciting beliefs depends on the interest of the researcher. If the researcher is interested in obtaining as much detailed information as possible, focus groups should be utilized. On the other hand, if the researcher is interested in obtaining the most common beliefs of participants 
regarding specific behaviors (as is the case when investigating behaviors with the $\mathrm{TpB}$ ), focus groups appear to be comparable to surveys. In this case, surveys may be the preferred method due to the time and cost issues associated with conducting focus groups. Focus groups and surveys are both useful, but they are useful for different types of tasks (i.e., obtaining specific, detailed information with focus groups versus obtaining the most salient information quickly and easily with surveys). While the conclusion of this study is that focus groups are useful for obtaining specific, detailed information, it should be noted that the information gained always depends on various factors such as the participants, the phrasing of questions, and the group's connection to the topic. The current study suggests that the data collection method (survey versus focus groups) also influences the information obtained.

With the results of this study, the authors suggest that when conducting research within the framework of the $\mathrm{TpB}$, researchers should first use surveys. This research found that surveys are comparable to focus groups when researchers are looking for the most salient beliefs, as is the case when using the TpB. Surveys may offer many benefits over focus groups as mentioned earlier. They can be easier to use, and they can save money and time. If after using surveys to collect data, the researcher is interested in gaining more specific, detailed information, they can then conduct focus groups. When making the decision to utilize surveys or focus groups for $\mathrm{TpB}$ belief elicitation, it is important to consider all costs associated with each method as they pertain to that unique situation. Costs will differ based on a variety of factors. There are several cost factors that need to be considered for focus groups (e.g., the training of the focus group leader, costs of rooms and refreshments) and surveys (printing of the surveys, mailing preparation and postage). Focus groups may be less expensive in some situations, such as if the researcher is already a trained focus group leader, if rooms are cost-free, and if the survey mailing would need 
to be outsourced. On the other hand, surveys may be much less expensive if someone would need to be trained to conduct the focus groups, if the rooms are only available at a cost, if there is cheap labor available to prepare the surveys, or if the surveys do not even need to be mailed (i.e., if a restaurant manager wants to quickly survey their own employees within the establishment). All of these cost factors should be taken into account when deciding which method to utilize. Beyond that, any results obtained through the two methods should be similar.

Though the results have implications for conducting research utilizing the $\mathrm{TpB}$ in general, the results also have important implications for understanding and improving restaurant employees' practices regarding food safety.

Limitations and Implications for Future Research. Limitations of the current study identify issues that should be investigated in future research. Though not possible in the current study, it would be interesting for future research to evaluate how individual's beliefs differ as a function of various demographic variables (e.g., age ranges, part-time vs. full-time employment, years of employment, prior training). It would also be interesting for future research to compare individuals' responses to the surveys and the focus groups to evaluate the influence of the group situation on individuals' responses. Future research could investigate why the results of the surveys and focus groups are different given that participants could refer to their completed surveys during the focus group. Perhaps it could be explained as an issue of the participants being stimulated from talking to other employees. Though the limited number of participants made it impossible to test these influences in the current study, future research could investigate whether having separate groups participate in the survey portion or the focus group portion would change the pattern of results. Resolving these issues may provide further insight into how the results can be applied to improve food safety in restaurants. 
Implications for Understanding Employees' Food Safety Practices. Both survey and focus group methodologies resulted in similar most frequently cited beliefs in regard to the three food safety behaviors. Across the three behaviors, it seems that restaurant employees do have an understanding that customers, employees, managers, and health inspectors care about them practicing proper food safety. They also have an appreciation for the necessity of proper food safety practices. They recognize that the advantages of proper food safety are fewer people getting ill, less cross contamination, and cleaner people and environment. Additionally, participants noted that the practices can improve food quality and customer satisfaction. Restaurant employees also indicate that disadvantages to food safety practices include taking time away from other tasks and just being an inconvenience in general. Restaurant employees suggest that certain things would make it easier to perform food safety behaviors such as more resources, more conveniently located resources, and managers monitoring employees' behaviors. Not surprisingly, the things that they list which make food safety practices more difficult to perform are lack of resources and inconveniently located resources.

Implications for Improving Employees' Food Safety Practices. The restaurant employees' most frequently cited beliefs in response to the perceived control questions could be used to help managers design a workplace intervention to improve food safety practices among food handlers. For example, across the three behaviors, participants mentioned similar factors that make it difficult to perform proper food safety practices, such as lack of resources (time, space, equipment, knowledge from training, etc.) and inconveniently located resources. Similarly, they believe it would be easier to perform the behaviors if they had more resources (knowledge from training, more time, more equipment, etc.), conveniently located resources, and managers who monitored their activities. Managers can take this cue from their food service 
employees and ensure that the employees receive training, have access to sufficient equipment, and that the equipment is located in a convenient place in the kitchen so employees will know where to find it. Additionally, it would be helpful for managers to let their employees know they care about food safety by monitoring employees' performance. Restaurant managers could even use the TpB to survey their own employees to identify barriers to various food safety practices specific to their establishment. Sanitarians can use the information provided by the current results during routine inspections to educate managers on ways they can encourage proper food safety practices among their food service employees. 


\section{References}

Ajzen, I. (1991). The theory of planned behavior. Organizational Behavior and Human Decision Processes, 50, 179-211.

Astrom, A. N., \& Mwangosi, I. E. (2000). Teacher's intention to provide dietary counseling in Tanzanian primary schools. American Journal of Health Behavior, 24, 281-289.

Boissonneault, E., \& Godin, G. (1990). The prediction of intention to smoke only in designated work site areas. Journal of Occupational Medicine, 32, 621-624.

Boudreau, F., Godin, G., Pineau, R., \& Bradet, R. (1995). Health risk appraisal in an occupational setting and its impact on exercise behavior. Journal of Occupational and Environmental Medicine, 37, 1145-1150.

Centers for Disease Control and Prevention. (2005). Foodborne illness: Frequently asked questions. Retrieved October 17, 2006, from http://www.cdc.gov/ncidod/dbmd/diseaseinfo/files/foodborne_illness_FAQ.pdf

Cohen, E., Reichel, A., \& Schwartz, Z. (2001). On the efficacy of an in-house training program: Statistical measurements and practical conclusions. Journal of Hospitality \& Tourism Research, 25(1), 5-16.

Coleman, G. J., McGregor, M., Hemsworth, P. H., Boyce, J., \& Dowling, S. (2003). The relationship between beliefs, attitudes and observed behaviours of abattoir personnel in the pig industry. Applied Animal Behaviour Science, 82, 189-200.

Collins, J. E. (1997). Impact of changing lifestyles on the emergence/reemergence of foodborne pathogens. Emerging Infectious Diseases, 3, 471-479. 
Conchran-Yantis, D., Belo, P., Giampaoli, J., McProud, L., Everly, V., \& Gans, J. (1996). Attitudes and knowledge of food safety among Santa Clara County, California restaurant operators. Journal of Foodservice Systems, 9, 117-128.

Cotterchio, M., Gunn, J., Coffill, T., Tormey, P., \& Barry, M. A. (1998). Effect of a manager training program on sanitary conditions in restaurants. Public Health Reports, 113, 353358.

Council for Agriculture Science and Technology. (1994). Foodborne pathogens: Risks and consequences. Council for Agriculture Science and Technology, Ames, IA.

Crawley, F. E., \& Koballa, T. R. (1992). Hispanic-American students' attitudes toward enrolling in high school chemistry: A study of planned behavior and belief-based change. Hispanic Journal of Behavioral Sciences, 14, 469-486.

Economic Research Service. (2004). Economics of foodborne disease: Estimating the benefits of reducing foodborne disease. Retrieved October, 17, 2006, from http://www.ers.usda.gov/briefing/FoodborneDisease/features.htm.

Economic Research Service. (1996). Bacterial foodborne disease: Medical costs and productivity losses (Report No. 741). Economic Research Service, Washington DC.

Food and Drug Administration. (2000). Report of the FDA retail food program database of foodborne illness risk factors. Retrieved June 21, 2002, from http://vm.cfsan.fda.gov/ dms/retrsk.html.

Food and Drug Administration. (2004). FDA report on the occurrence of foodborne illness risk factors in selected institutional foodservice, restaurant, and retail food store facility types. Retrieved June 25, 2006, from http://www.cfsan.fda.gov/ acrobat/retrsk2.pdf. 
Flannery, B. L., \& May, D. R. (2000). Environmental ethical decision making in the U.S. metalfinishing industry. Academy of Management Journal, 43, 642-662.

Godin, G., Naccache, H., \& Fortin, C. (1998). Understanding physicians' intention to use a simple infection control measure: Wearing gloves. American Journal of Infection Control, 26, 413-417.

Godin, G., Naccache, H., Morel, S., \& Ebacher, M. (2000). Determinants of nurses' adherence to Universal Precautions for venipunctures. American Journal of Infection Control, 28, 359364.

Harrison, D. A., \& Liska, L. Z. (1994). Promoting regular exercise in organizational fitness programs: Health-related differences in motivational building blocks. Personnel Psychology, 47, 47-71.

Howes, M., McEwen, S., Griffith, M., \& Harris, L. (1996). Food handler certification by home study: Measuring changes in knowledge and behavior. Dairy, Food, \& Environmental Sanitation, 16, 737-744.

James, A. S., Tripp, M. K., Parcel, G. S., Sweeney, A., \& Gritz, E. R. (2002). Psychological correlates of sun-protective practices of preschool staff toward their students. Health Education Research, 17, 305-314.

Jenner, E. A., Watson, P. W. B., Miller, L., Jones, F., \& Scott, G. M. (2002). Explaining hand hygiene practice: An extended application of the theory of planned behaviour. Psychology, Health \& Medicine, 7, 311-326.

Kneller, P., \& Bierma, T. (1990). Food service certification - Measuring effectiveness of a state program. Journal of Environmental Health, 52 (5), 292-294. 
Kurland, N. B. (1995). Ethical intentions and the theories of reasoned action and planned behavior. Journal of Applied Social Psychology, 25, 297-313.

Levin, P. F. (1999). Test of the Fishbein and Ajzen models as predictors of health care workers' glove use. Research in Nursing and Health, 22, 295-307.

Liabsuetrakul, T., Chongsuvivatwong, V., Lumiganon, P., \& Lindmark, G. (2003).

Obstetricians' attitudes, subjective norms, perceived controls, and intentions on antibiotic prophylaxis in caesarean section. Social Science \& Medicine, 57, 1665-1674.

McCarty, M. C., Hennrikus, D. J., Lando, H. A., \& Vessey, J. T. (2001). Nurses’ attitudes concerning the delivery of brief cessation advice to hospitalized smokers. Preventive Medicine, 33, 674-681.

McElroy, D. M., \& Cutter, C. N. (2004). Self-reported changes in food safety practices as a result of participation in a statewide food safety certification program. Food Protection Trends, 24, 150-161.

Martin, J. J., Hodges-Kulinna, P., Eklund, R. C., \& Reed, B. (2001). Determinants of teachers' intentions to teach physically active physical education classes. Journal of Teaching in Physical Education, 20, 129-143.

Millstein, S. G. (1996). Utility of the theories of reasoned action and planned behavior for predicting physician behavior: A prospective analysis. Health Psychology, 15, 398-402.

Nash, R., Edwards, H., \& Nebauer, M. (1993). Effect of attitudes, subjective norms and perceived control on nurses' intention to assess patients' pain. Journal of Advanced Nursing, 18, 941-947.

National Restaurant Association Educational Foundation. (2004). ServSafe Coursebook (3rd ed.). National Restaurant Association Educational Foundation, Chicago. 
O’Boyle, C. A., Henly, S. J., Larson, E. (2001). Understanding adherence to hand hygiene recommendations: The theory of planned behavior. American Journal of Infection Control, 29, 352-360.

Olsen, S. J., MacKinon, L. C., Goulding, J. S., Bean, N. H., \& Slutsker, L. (2000). Surveillance for foodborne disease outbreaks - United States, 1993-1997. MMWR, 49 (SS01), 1-51.

Randall, D. M., \& Gibson, A. M. (1991). Ethical decision-making in the medical profession: An application of the theory of planned behavior. Journal of Business Ethics, 10, 111-122.

Riben, P. D., Mathias, R. G., Wiens, M., Cocksedge, W., Hazelwood, A., Kirshner, B., \& Pelton, J. (1994). Routine restaurant inspections and education of food handlers:

Recommendations based on critical appraisal of the literature and survey of Canadian jurisdictions on restaurant inspections and education of food handlers. Canadian Journal of Public Health, 85 (Suppl. 1), 567-570.

Roberts, K. R., Barrett, B., \& Sneed, J. (2005). Health department sanitarians perception of food safety practices in restaurants. Food Protection Trends, 25, 694-700.

Roberts, K. R., \& Sneed, P. J. (2003). An assessment of the status of prerequisite and HACCP programs in Iowa Restaurants. Food Protection Trends, 23, 808-816.

Sheehan, M., Schonfeld, C., Ballard, R., Schofield, F., Najman, J., \& Siskind, V. (1996). A three year outcome evaluation of a theory based drink driving education program. Journal of Drug Education, 26, 295-312.

Sheeran, P., \& Silverman, M. (2003). Evaluation of three interventions to promote workplace health and safety: Evidence for the utility of implementation intentions. Social Science \& Medicine, 56, 2153-2163. 
Sparks, P., \& Shepherd, R. (2002). The role of moral judgments within expectancyvalue-based attitude-behavior models. Ethics \& Behavior, 12, 299-32.

Sparks, P., Shepherd, R., \& Frewer, L. J. (1995). Assessing and structuring attitudes toward the use of gene technology in food production: The role of perceived ethical obligation. Basic and Applied Social Psychology, 16, 267-285. 
Table 1

Table 1. Definitions of Food Safety Behaviors of Interest

\section{PROPER HANDWASHING:}

- Washing with soap and hot water for 20 seconds

- Drying (with an air dryer or single use paper towels)

- Washing hands before work

- Washing hands before putting on gloves

- Washing hands when food preparation tasks are interrupted or changed

- Washing hands whenever they come in contact with something that might have germs (food, the bathroom, coughing, or touching body parts)

USING A THERMOMETER TO CHECK THE TEMPERATURE OF FOOD:

- At the completion of cooking (various temperatures)

- At the completion of reheating (to 165 degrees)

- To ensure that food stored on the hot line is at least 135 degrees

- To ensure that food stored on the cold line is 41 degrees or less

PROPER HANDLING OF FOOD AND WORK SURFACES BY:

- Not allowing raw food to come into contact with ready-to-eat foods.

- Cleaning and sanitizing all food contact surfaces (hands/gloves, countertops, cutting surfaces, equipment, dishes \& utensils) between each use.

- Cleaning and sanitizing all food contact surfaces when switching from one food preparation task to another. 


\begin{tabular}{|c|c|c|c|c|}
\hline \multirow{2}{*}{ Food Handling Practice } & \multirow{2}{*}{ TpB Category } & \multicolumn{2}{|c|}{ Method } & \multirow{2}{*}{$\begin{array}{l}\text { Additional Number of Items } \\
\text { Elicited with Focus Groups }\end{array}$} \\
\hline & & Focus Group & Survey & \\
\hline \multirow[t]{4}{*}{ Handwashing } & Advantages & 9 & 9 & 0 \\
\hline & Disadvantages & 7 & 7 & 0 \\
\hline & Facilitators & 15 & 11 & 4 \\
\hline & Barriers & 15 & 13 & 2 \\
\hline \multirow[t]{4}{*}{ Using Thermometers } & Advantages & 8 & 8 & 0 \\
\hline & Disadvantages & 7 & 6 & 1 \\
\hline & Facilitators & 21 & 14 & 7 \\
\hline & Barriers & 17 & 13 & 4 \\
\hline \multirow[t]{4}{*}{ Cleaning Work Surfaces } & Advantages & 14 & 11 & 3 \\
\hline & Disadvantages & 5 & 6 & $\begin{array}{ll}-1 \\
\end{array}$ \\
\hline & Facilitators & 19 & 18 & 1 \\
\hline & Barriers & 15 & 16 & -1 \\
\hline All Behaviors Combined & Subjective Norms & 9 & 8 & 1 \\
\hline
\end{tabular}




\begin{tabular}{l|c|c|}
\hline \hline \multirow{2}{*}{ Table 3a. Most Frequent Responses in Focus Groups (N=10) and Surveys (N=34) for Handwashing } \\
\hline \hline \multirow{2}{*}{ Component of Theory of Planned Behavior } & \multicolumn{2}{|c|}{ Method } \\
\cline { 2 - 3 } & Focus Group & Survey \\
\hline Advantages & & 67.6 \\
\hline Food safety & 100.0 & 44.1 \\
\hline Reduce cross contamination & 90.0 & 44.1 \\
\hline Personal hygiene & 80.0 & - \\
\hline Customer satisfaction & 70.0 & 14.7 \\
\hline Other & - & \\
\hline Disadvantages & & 50 \\
\hline Takes time & 90.0 & - \\
\hline Competes with other tasks & 90.0 & 17.6 \\
\hline Dry hands & 70.0 & - \\
\hline Inconvenience & 60.0 & 14.7 \\
\hline Cost & $60 / 0$ & 29.4 \\
\hline Facilitator & & 47.1 \\
\hline Sinks available & 100.0 & - \\
\hline Sinks conveniently located & 90.0 & 17.6 \\
\hline More time & 90.0 & 17.6 \\
\hline Training on how to wash hands & 80.0 & \\
\hline Enough towels & - & 58.8 \\
\hline Barriers & & 14.7 \\
\hline Not enough time & 100.0 & 11.8 \\
\hline Resources inconveniently located & 80.0 & 14.7 \\
\hline Competing tasks & 60.0 & - \\
\hline Employee attitude & 50.0 & - \\
\hline Sinks unavailable & 50.0 & 50.0 \\
\hline Training on how and when to wash hands & & \\
\hline \hline & & \\
\hline
\end{tabular}




\begin{tabular}{l|c|c|}
\hline \hline Table 3b. Most Frequent Responses in Focus Groups (N=10) and Surveys (N=34) for Thermometers \\
\hline \hline \multirow{2}{*}{ Component of Theory of Planned Behavior } & \multicolumn{2}{|c|}{ Method } \\
\cline { 2 - 3 } & Focus Group & Survey \\
\hline Advantages & & 35.3 \\
\hline Food quality & 100.0 & 47.1 \\
\hline Food safety & 100.0 & 20.6 \\
\hline Customer satisfaction & 80.0 & 50 \\
\hline Ensures correct temperature & 70.0 & \\
\hline Disadvantages & & 38.2 \\
\hline Cross contamination & 90.0 & 14.7 \\
\hline Takes time & 90.0 & 14.7 \\
\hline Doing it wrong & 80.0 & 11.8 \\
\hline Competes with other tasks & 40.0 & 11.8 \\
\hline Employee attitude & - & - \\
\hline Facilitators & & 17.6 \\
\hline Training on correct temperatures for foods & 90.0 & 17.6 \\
\hline Thermometers available & 80.0 & 17.6 \\
\hline Managers monitoring & 80.0 & - \\
\hline Training on how to use thermometers & 80.0 & 29.4 \\
\hline Signs with correct temperatures & 80.0 & \\
\hline Thermometers conveniently located & - & 44.1 \\
\hline Barriers & & 20.6 \\
\hline Lack of time & 90.0 & - \\
\hline Lack of thermometers & 90.0 & - \\
\hline Lack of training on correct temperatures & 70.0 & 11.8 \\
\hline Lack of training on how to use thermometer & 70.0 & \\
\hline Thermometers inconveniently located & - & \\
\hline \hline
\end{tabular}




\begin{tabular}{|l|c|c|}
\hline \hline \multirow{2}{*}{ Table 3c. Most Frequent Responses in Focus Groups (N=10) and Surveys (N=34) for Work Surfaces } \\
\hline \hline \multirow{2}{*}{ Component of Theory of Planned Behavior } & \multicolumn{2}{|c|}{ Method } \\
\cline { 2 - 3 } & Focus Group & Survey \\
\hline Advantages & & 32.4 \\
\hline Reduce cross contamination & 90.0 & - \\
\hline Customer satisfaction & 90.0 & 64.7 \\
\hline Food safety & 80.0 & 32.4 \\
\hline Clean work area & 70.0 & 20.6 \\
\hline Protect establishment from lawsuit & 70.0 & 23.5 \\
\hline Safety of customers & - & \\
\hline Disadvantages & & 70.6 \\
\hline Takes time & 100.0 & 14.7 \\
\hline Carelessness leading to chemical contamination & 60.0 & 20.6 \\
\hline Inconvenience & 50.0 & 11.8 \\
\hline Employee attitude & 30.0 & - \\
\hline Cost & 30.0 & 17.6 \\
\hline Facilitators & & 17.6 \\
\hline More time & 90.0 & 29.4 \\
\hline Managers monitoring & 90.0 & 20.6 \\
\hline Resources conveniently located & 70.0 & 20.6 \\
\hline Training on how and when & 70.0 & \\
\hline Equipment available & - & 67.6 \\
\hline Barriers & & 20.6 \\
\hline Lack of time & 100.0 & - \\
\hline Employee attitude & 80.0 & 11.8 \\
\hline Lack of training & 80.0 & - \\
\hline Lack of space & 60.0 & - \\
\hline Lack of training on consequences & 60.0 & 14.7 \\
\hline Lack of resources & 60.0 & \\
\hline Inconvenience & - & \\
\hline \hline
\end{tabular}


